\title{
Contribution of Forensic Odontology Face of the Shortcomings of DNA Identification: The Effect of the Dental Morphology
}

\section{Nemsi $\mathbf{H}^{*}$}

Oral Health and Oral Rehabilitation Research Laboratory (LR12ES11), Faculty of Dental Medicine, Monastir University, 5000 Monastir, Tunisia

\begin{abstract}
The advent of genomic and mitochondrial DNA procedures has not displaced the practical use of dental identification after mass disasters or when bone DNA extraction is impossible. Sometimes the ethical aspect is the basic aim of the identification. In this forensic case the purpose of identification was to give psychological comfort to the mother that she has doubted about the identity of the remains of his presumed son. The forensic odontologist occupying a crucial role in the identification of human remains. Without being able to identify the presence of the \#18 not the \#17 and especially the \#47 not the \#46 identity would be improperly excluded.
\end{abstract}

Keywords: Forensic odontology; Fingerprints; DNA extraction; Periapical radiograph

\section{Introduction}

Identify a deceased subject is a fundamental element of the forensic examination in fact; identity is basic to the criminal pursuit and is essential in certain civil actions. Also there is a real ethical aspect in the identity determination. All the process of identification, from the analysis of fingerprints to dental identification or even DNA examination, is established by a comparative process. The teeth have a high resistance to the agents who induce the destruction of the corpses (putrefaction, traumatic, physical and chemical agents) and a high morphological variability. Numerous studies have proven conclusively the uniqueness of the human dentition, the results of a research developed by Madi et al. [1] revealed that the dental characteristics show a diversity that is useful for human identification even when those characteristics are recorded in their simplest forms. In another study about the utility of dental patterns in forensic dentistry, Martinde-las-Heras et al. [2] concluded that the conditional diversity value derived from dental patterns is a potentially valuable tool with broad applicability for human identification. Keiser-Nielsen [3] reported that there are more than 2.5 billion possibilities in charting the human characterization. The intervention of Forensic Dentistry in some cases may represent the only solution to achieve a positive identification of an unidentified bodies or when we have a doubtful identity [4]. In this context, the present study aims to report a case in which human skeletal remains were identified due to a perfect knowledge of dental anatomy. The presented case is an example of how decisive is the collaboration of experts representing different forensic areas.

\section{Case Report}

\section{History event}

Human remains exhumed for a forensic comparative identification are the matter of this paper. It would probably be the skeletal remains of a young Tunisian man lived in France and was born in 1981, victim of the terrorist attack in London on 7 July 2005 at the metro station "Russell Square". The skeletal remains are supposed identified by facial recognition and personal papers by the British authorities. However, it was not convincing for the presumed mother of the victim and she has doubted the identity of the remains after five years of the inhumation. For that, the public prosecutor has requested a comparative identification procedure. The exhumation done in 19.04.2010. Upper and lower jaws with their teeth and femur were recovered.
A femur fragment was sent for comparative genomic identification. However, DNA extraction was impossible due to the advance state of decomposition of the bone. A comparison of dental records was the last resort to determine the identity of the remains. At the beginning of the expertise there was not a forensic odontologist among forensic team. Following an identification difficulties a forensic odontologist was recruited. The evidence taken into consideration included an antemortem dental chart and an impression of a periapical radiovisiographic image. They were sent by the treating dentist in France. The jaws with their teeth were our postmortem support.

\section{Post mortem evidence}

For the first time the fragmented upper (Figure 1) and lower

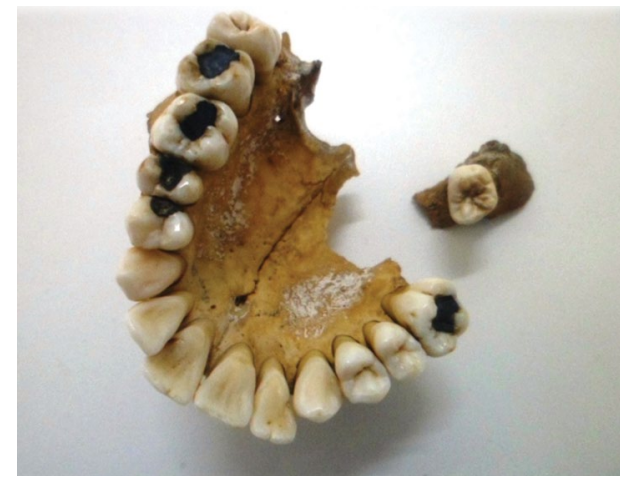

Figure 1: Fragmented upper jaws with teeth.

*Corresponding author: Nemsi $\mathrm{H}$, Oral Health and Oral Rehabilitation Research Laboratory (LR12ES11), Faculty of Dental Medicine, Monastir University, 5000 Monastir, Tunisia, Tel: 73460832, E-mail: hichem_ne@yahoo.fr

Received December 01, 2016; Accepted December 06, 2017; Published December 12, 2017

Citation: Nemsi H (2017) Contribution of Forensic Odontology Face of the Shortcomings of DNA Identification: The Effect of the Dental Morphology. J Forensic Res 8: 402. doi: 10.4172/2157-7145.1000402

Copyright: (c) $2017 \mathrm{Nemsi} \mathrm{H}$. This is an open-access article distributed under the terms of the Creative Commons Attribution License, which permits unrestricted use, distribution, and reproduction in any medium, provided the original author and source are credited. 
Citation: Nemsi H (2017) Contribution of Forensic Odontology Face of the Shortcomings of DNA Identification: The Effect of the Dental Morphology. J Forensic Res 8: 402. doi: 10.4172/2157-7145.1000402

Page 2 of 4

(Figure 2) jaws were examined by a forensic physician and the results of the postmortem odontological investigation are shown in (Table 1).

The two digits of the FDI system were used to designed teeth.

After forensic odontologist recruitment, two critical mistakes that will be conclusive in the identification procedure were mentioned. These mistakes were from the area of the dental anatomy.

First one: Confusion between teeth: \#17 and \#18

The tooth separated from the upper jaw with an attached bone fragment (Figure 3) is the upper right third molar not upper right second molar. Since the treating dentist was mentioned that the last visit was in 27.07.2000, so five years before the attack, the upper right second molar could be extracted by another dentist.

Although, the maxillary third molars have the greatest morphologic variance of all teeth they have certain type traits in common that set them distinct from the second molars.

In our case we can note that:

-The crown of the separated teeth is smaller than crown of the first and second molars in the same jaw.

- Occlusal table is relatively smaller compared to other molars.

- Occlusal surface is quite wrinkled due to numerous supplemental grooves and ridges.

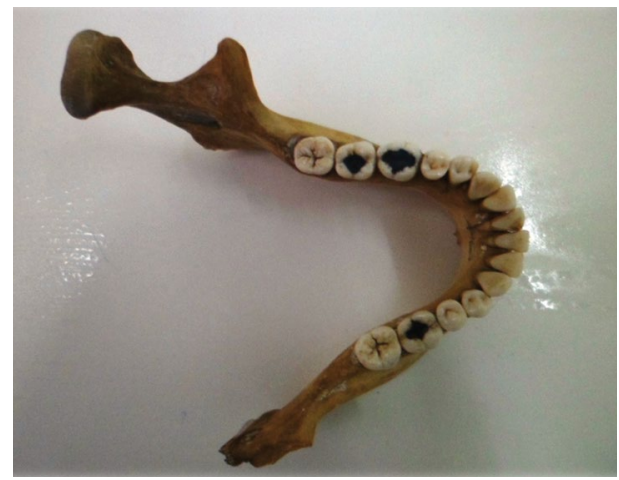

Figure 2: Mandibular jaw with teeth

\begin{tabular}{|c|c|c|c|}
\hline$\# 11$ & Sound & $\# 31$ & Sound \\
\hline$\# 12$ & Sound & $\# 32$ & Sound \\
\hline$\# 13$ & Sound & $\# 33$ & Sound \\
\hline$\# 14$ & Sound & $\# 34$ & Sound \\
\hline$\# 15$ & Sound & $\# 35$ & Sound \\
\hline$\# 16$ & Filled Am & $\# 36$ & Filled Am O \\
\hline$\# 17$ & Sound & $\# 37$ & Filled Am O \\
\hline$\# 18$ & Missed on Antemortem & $\# 38$ & Sound \\
\hline$\# 21$ & Sound & $\# 41$ & Sound \\
\hline$\# 22$ & Sound & $\# 42$ & Sound \\
\hline$\# 23$ & Sound & $\# 44$ & Sound \\
\hline$\# 24$ & Filled Am OD & $\# 45$ & Sound \\
\hline$\# 25$ & Filled Am OD & $\# 46$ & Filled Am O \\
\hline$\# 26$ & Filled Am O & $\# 47$ & Filled Am O \\
\hline$\# 27$ & Filled Am O & $\# 48$ & Agenesis \\
\hline$\# 28$ & Sound & & \\
\hline
\end{tabular}

Table 1: Postmortem dental records. Am: Amalgam; O: Occlusal; D: Distal
- Roots are fused.

- Distolingual cusp is very small.

Finally there are an attached socket bone completely healed in the mesial side of the tooth (the upper right second molar \#17 very likely was lost several months before death) and a maxillary tuberosity in distal side.

Second one: Confusion between teeth: \#46 and \#47.

The tooth following the lower right second premolar \#45 (Figure 4 ) is the lower right second molar \#47 not the lower right first molar \#46. Consequently, the right third molar \#48 existed. Mandibular first (Figure 5) and second molars (Figure 6) have specific traits that can be used to distinguish one from the other (Table 2 and 3 ).

A result of this dental record investigation we can pronounce that:

-The right mandibular first molar \#46 is very likely extracted at an age not far away from 12 years. Because the second molar (erupts around 12 years) accuratly took the place of the \#46.

-The right mandibular second molar \#47 is filled with occlusal amalgam.

-The right mandibular third molar \#48 is sound.

A periapical radiograph of the \#36 and \#37 was done (Figure 7).

\section{Further clinical findings:}

- Any smoking pigmentation. SAL

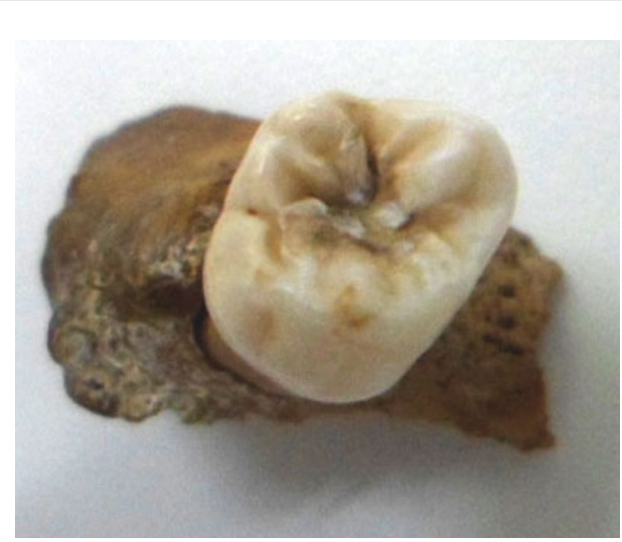

Figure 3 : The right maxillary third molar \#18.

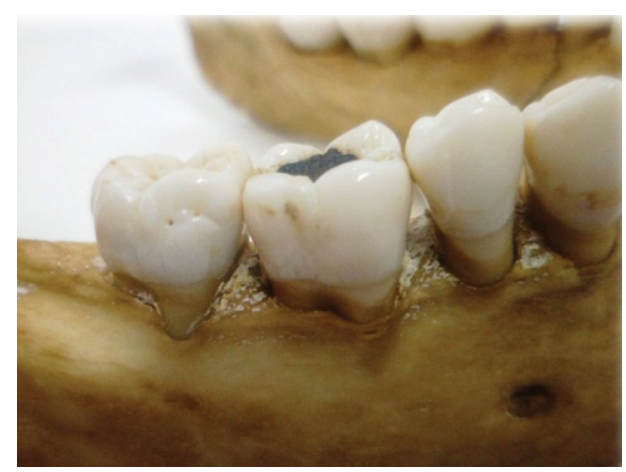

Figure 4: The lower right second molar \#47: Buccal view. 
Citation: Nemsi H (2017) Contribution of Forensic Odontology Face of the Shortcomings of DNA Identification: The Effect of the Dental Morphology. J Forensic Res 8: 402. doi: 10.4172/2157-7145.1000402

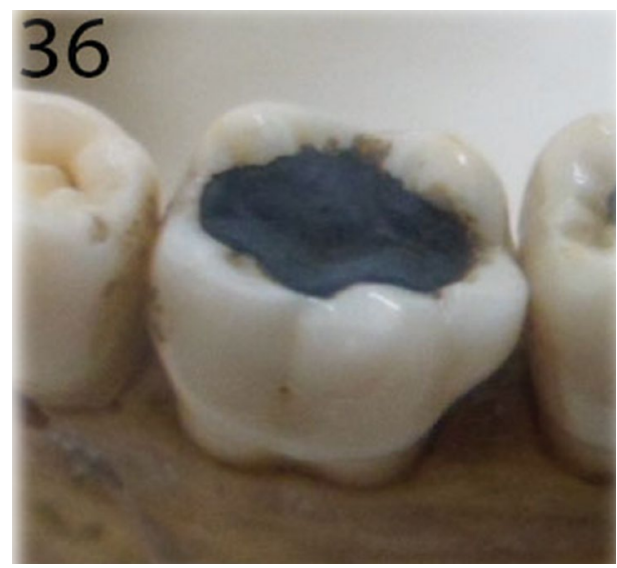

Figure 5: Mandibular left first molar \#36.

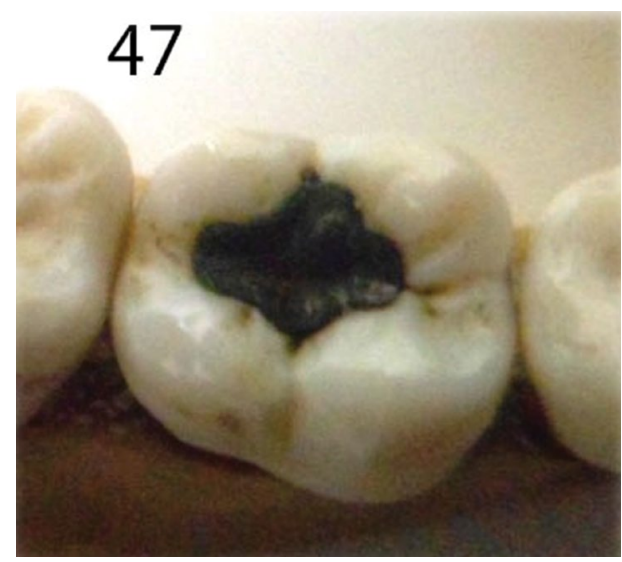

Figure 6: The lower right second molar \#47.

\begin{tabular}{|l|l|}
\hline Mandibular First Molar (\#36) & Mandibular Second Molar (\#47) \\
\hline $\begin{array}{l}\text { Three buccal cusps: mesiobuccal, } \\
\text { distobuccal, and distal }\end{array}$ & $\begin{array}{l}\text { Two buccal cusps: mesiobuccal and } \\
\text { distobuccal }\end{array}$ \\
\hline $\begin{array}{l}\text { Two buccal grooves: mesiobuccal and } \\
\text { distobuccal }\end{array}$ & One buccal groove \\
\hline
\end{tabular}

Table 2: Traits to distinguish the mandibular first molar (\#36 in our case) from the mandibular second molar (\#47 in our case): Buccal view (4).

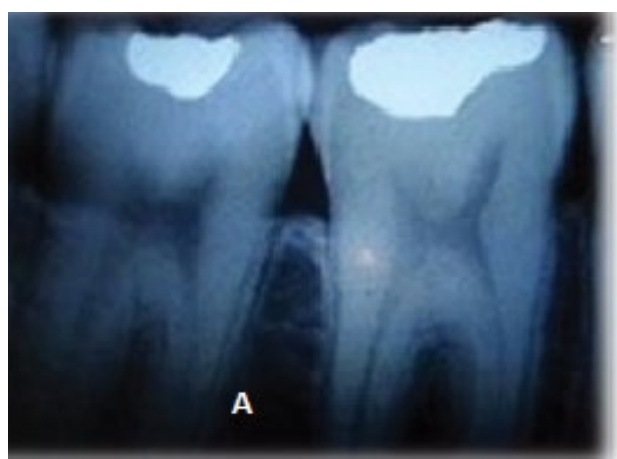

Figure 7: Periapical radiograph of \#36 and \#37.

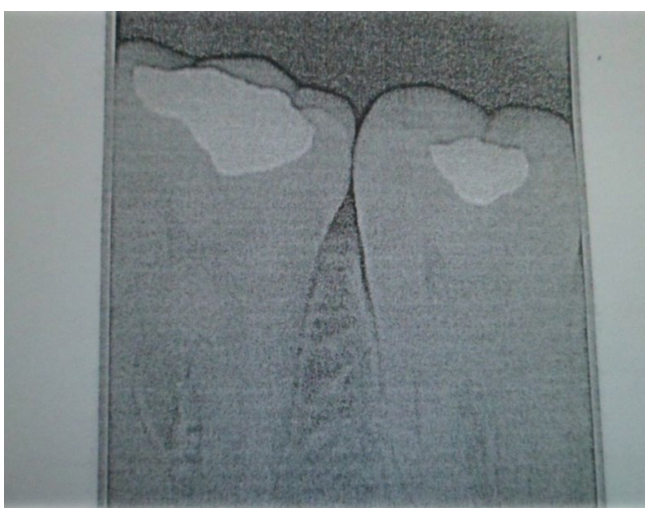

Figure 8: Impression of a periapical radiovisiographic image.
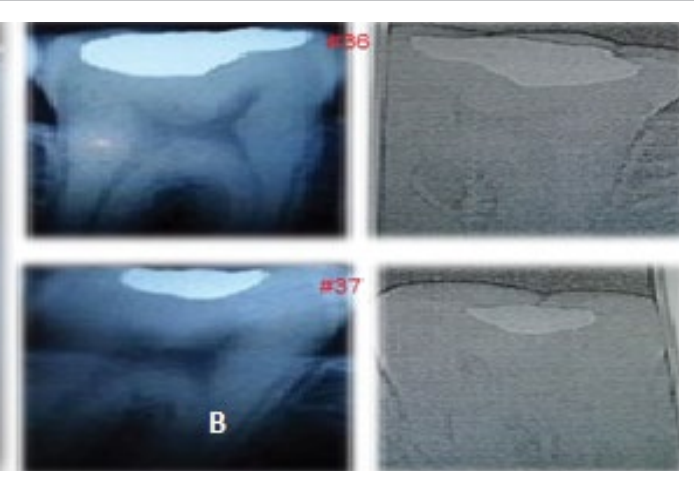

\begin{tabular}{|c|c|}
\hline Mandibular First Molar (\#36) & Mandibular Second Molar (\#47) \\
\hline Five cusps: three buccal and two lingual & $\begin{array}{l}\text { Four cusps : two buccal and two } \\
\text { lingual }\end{array}$ \\
\hline $\begin{array}{l}\text { Pentagon shape and the highest mesio } \\
\text { distal width }\end{array}$ & $\begin{array}{l}\text { Rectangular shape and moderate } \\
\text { mesio distal width }\end{array}$ \\
\hline Fewer secondary grooves & More secondary grooves \\
\hline $\begin{array}{l}\text { Mesiobuccal and distobuccal grooves do not } \\
\text { align with lingual groove }\end{array}$ & $\begin{array}{l}\text { Buccal groove align with the } \\
\text { lingual groove }\end{array}$ \\
\hline
\end{tabular}

Table 3: Traits to distinguish mandibular first molar from mandibular second molar Occlusal view (4).

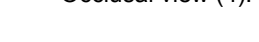

\begin{tabular}{|c|c|c|c|}
\hline$\# 11$ & Sound & $\# 31$ & Sound \\
\hline$\# 12$ & Sound & $\# 32$ & Sound \\
\hline$\# 13$ & Sound & $\# 33$ & Sound \\
\hline$\# 14$ & Sound & $\# 34$ & Sound \\
\hline$\# 15$ & Sound & $\# 35$ & Sound \\
\hline$\# 16$ & Filled Am O on 24.01.1994 & $\# 36$ & Filled Am O on 11.01.1994 \\
\hline$\# 17$ & Carious & $\# 37$ & Filled Am O on 11.01.1994 \\
\hline$\# 18$ & Any information & $\# 38$ & Any information \\
\hline$\# 21$ & Sound & $\# 41$ & Sound \\
\hline$\# 22$ & Sound & $\# 42$ & Sound \\
\hline$\# 23$ & Sound & $\# 43$ & Sound \\
\hline$\# 24$ & Filled Am OD on 05.03.1996 & $\# 44$ & Sound \\
\hline$\# 25$ & Filled Am OD on 05.03.1996 & $\# 45$ & Sound \\
\hline$\# 26$ & Filled Am O on 27.07.2000 & $\# 46$ & Extracted on 22.12.1993 \\
\hline$\# 27$ & Filled Am O on 24.01.1994 & $\# 47$ & Filled Am O on 24.01.1994 \\
\hline$\# 28$ & Any information & $\# 48$ & Any information \\
\hline
\end{tabular}

Table 4: Antemortem dental records. 
- Minimal alveolar bone lose without visibility of the furcation area of the teeth.

- Any morphological alterations of the crowns.

- Occlusion with canine guide.

\section{Ante mortem evidence}

Periapical radiograph (Figure 8) showed the first and the second lower left molars \#36 and \#37 and a written clinical record were eventually received from the treating dentist following the request of the public prosecutor (Table 4)

\section{Comparison report and Discussion}

\section{Sex and age estimation}

The gender-specific characteristics [5-7] indicated the mandible of a man. The degree of attrition on the teeth, the level of socket bone and the volume of the pulp cavity of the tooth indicated that the jaws belong to a young adult. Therefore sex and age are concordant with those of the presumed victim.

\section{Odontological investigation}

The comparison of ante mortem and post mortem dental records revealed the following concordances:

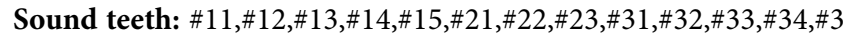
5,\#41,\#42,\#43,\#44,\#45.

Any information was communicated by the treating dentist about the third molars, so they are excluded from the comparison.

Filled teeth : \#16,\#26,\#27,\#36,\#37,\#47 : occlusal amalgam filled

\#24, \#25: occluso distal amalgam filled

Extracted teeth: \#46 in 22.12.1993, the presumed victim was 12 years old. Consequently, the second molar \#47 exactly took the place of the first molar \#46.

The maxillary right second molar \#17 was carious, according to the ante mortem records. Therefore, it very likely was extracted many months before death, regarding the attached socket bone completely healed in the mesial side of the tooth \#18.

Radiographic investigation : A superposition of amalgam margins in the ante and post mortem radiographs is evident. The current forensic case presented at all 27 concordant dental records without any unexplainable discrepancies. Keiser-Nielsen [8] announced three conclusion: Firstly, the established identity (when we have 12 or more uncharacteristic concordant features), then the probable identity (when we have between 8 and 11 uncharacteristic concordant features) finally the possible identity (when we have less than 8 concordant details). Already, it was the standard recommanded by the Interpol form. Acharya et al. [9] concluded that there appears to be no basis for defining a minimum number of concordant points necessary before a positive identification can be made on dental evidence. Each case has its own individuality and should be treated as such. It is evident that the concordance in sound teeth is not enough uncharacteristic to declare an established identity whatever its number. Filled teeth are more specific especially when two faces are involved (ten faces in our case). Many factors can influence the outcome of an identification investigation. In this case the extraction of the mandibular right first molar at an age of 12 years and the periapical radiographs concordances were the strongest evidences which played a crutial role in the identification process, allow us to conclude that the identity was established. This confirmed identity provided much moral comfort for the mother's victim.

\section{Conclusion}

The mastery of morphologic crown characteristics of permanent mandibular first and second molars was crucial to transform a discrepancy point to an evidence element for positive identification. Without being able to identify the presence of the \#18 not the \#17 and especially the \#47 not the \#46, we could have an insurmountable discrepancy. The identity could be abusively excluded. This case report underline the value of a forensic odontologist as a part of the forensic team during an identification process of human remains. In addition, we can conclude that the common anthropology still has its part despite the scientific progress in DNA identification.

\section{References}

1. Madi HA, Swaid S, Al-Amad S (2013) Assessment of the uniqueness of human dentition. J Forensic Odontostomatol 31: 30-39.

2. Martin-de-Las-Heras S, Valenzuela A, Luna Jde D, Bravo $M(2010)$ The utility of dental patterns in forensic dentistry. Forensic Sci Int 195: 166.e1-5

3. Keiser-Nielsen S (1977) Dental identification: Certainty vs. probability. Forensic Sci 9: 87-97.

4. Rickne CS (2012) Woelfel's Dental Anatomy ( $8^{\text {th }}$ edn.), Wolters Kluwer Health Copyright. Lippincott Williams \& Wilkins. Philadelphia, PA 19103 USA

5. Ramsthaler F, Kettner M, Gehl A, Verhoff MA (2010) Digital forensic osteology: Morphological sexing of skeletal remains using volume-rendered cranial CT Scans. Forensic Sci Int 195: 148-152.

6. Ramsthaler F, Kreutz K, Verhoff MA (2007) Accuracy of metric sex analysis of skeletal remains using Fordisc based on a recent skull collection. Int $\mathrm{J}$ Legal Med 121: 477-482.

7. Saini V, Srivastava R, Rai RK, Shamal SN, Singh TB, et al. (2011) Mandibular ramus: An indicator for sex in fragmentary mandible. J Forensic Sci 1: S13-6.

8. Keiser-Nielsen S (1980) Person identification by means of the teeth. Bristol: Wright 21: 114.

9. Acharya AB, Taylor JA (2003) Are a minimum number of concordant matches needed to establish identity in forensic odontology? J Forensic Odontostomatol. 21: $6-13$. 